\title{
Parenting Support for Health Care Workers During the COVID-19 Pandemic: An Institutional Survey and Resources
}

\author{
Sukjoo Cho, MD - Melinda Murphy, MD ${ }^{1,2}$ - Rebecca Plant, MD,2
}

The spread of COVID-19 and corresponding mitigation measures resulted in widespread disruptions for parents/guardians and children in daily life. A recent national survey of parents reported that loss of regular childcare affected nearly a quarter of respondents.' Health care workers have essential roles during the pandemic and are particularly susceptible to these disruptions. Yumiko Aoyagi and colleagues reported that childcare obligations were significantly associated with health care workers' unwillingness to work during an influenza pandemic. ${ }^{2}$ Absenteeism in the health care workforce caused by childcare obligations adversely affect health care capacity, which could increase cumulative mortality from COVID-19. ${ }^{3}$ Therefore, the authors of this review conducted an institutional survey to assess the needs of health care workers who are parents/guardians during the COVID-19 pandemic, assisted in the design and implementation of strategies to address these needs, and suggested additional resources and strategies.

\section{METHODS}

In August 2020, a confidential survey was sent to the Department of Pediatrics at the University of South Florida using an online survey platform. Respondents included faculty members, clinic staff, and administration staff who were not associated with patient care. They were asked to respond to 9 items, including 8 multiple choice and 1 short answer questions. Questions addressed parents' current needs for childcare: the age and number of children, currently available childcare options, and personal levels of stress for seeking childcare for the upcoming school year. At the time of the survey, schools were closed for in-person attendance. The primary hypothesis was that health care-provider parents during

\section{AFFILIATIONS:}

'Department of Pediatrics, University of South Florida, Tampa, Florida

${ }^{2}$ Department of Pediatrics, Morsani College of Medicine, Tampa, Florida

\section{CITATION:}

Cho S, Murphy M, Plant R. Parenting support for health care workers during the COVID-19 pandemic: an institutional survey and resources. Consultant. Published online October 18, 2021. doi:10.25270/ con.2021.10.00006

Received March 22, 2021. Accepted May 28, 2021.

\section{DISCLOSURES:}

The authors report no relevant financial relationships.

\section{ADDITIONAL CONTRIBUTIONS:}

The authors would like to thank Dr Jane Carver for her assistance in editing and direction of this manuscript. The authors would like to acknowledge Dr Patricia Emmanuel, Lewis A. Barness Endowed Pediatric Departmental Chair at the University of South Florida, for her unwavering support of this endeavor and her department during the pandemic.

\section{CORRESPONDENCE:}

Rebecca Plant, MD, Department of Pediatrics, University of South Florida, 2 Tampa General Circle, 5th Floor, Tampa, FL 33606 (rplant@usf.edu)

the COVID-19 pandemic do not have adequate options of support for childcare. The secondary aim was to address these options and provide resources for the pediatrics department's employees.

\section{RESULTS}

A total of 99 responses were received from a department of 448 employees (total, including those without children) including physicians, residents, other practitioners, nurses, medical assistants, office staff, and other clinical staff. Of the responses, $42 \%$ were faculty, $12 \%$ were office staff who did not provide patient care, $34 \%$ were clinical staff, and $12 \%$ were other areas within the department, such as community outreach personnel, service coordinators, administrators, and residents. Respondents worked at a variety of sites, including 2 children's hospitals, 3 multidisciplinary academic outpatient clinics, 2 hospital-owned multidisciplinary outpatient clinics, a tertiary referral children's hospital near Tampa, Florida, and on the campus of the University of South Florida in Tampa, Florida.

A total of 125 children were reported by health care workers who were parents (Table). About $70 \%$ of the children were in elementary school or younger (87 of 125 children) and required childcare services.

Options that parents had for childcare and/or e-learning at the time of the survey included staying home with household member (20\%), enrolling in private school (18\%), using paid time off from work (18\%), and using unpaid time off from work (13\%). Other options included e-learning pods, hiring a nanny or private 
Table. Number of Children By Age, as Reported By Health Care-Provider Parents

\begin{tabular}{|c|c|c|}
\hline & $\begin{array}{l}\text { NUMBER OF } \\
\text { CHILDREN }\end{array}$ & $\begin{array}{l}\text { PERCENTAGE OF TO- } \\
\text { TAL CHILDREN }\end{array}$ \\
\hline Infant (o-11 months) & 3 & $2 \%$ \\
\hline Toddler (12 months-4 years) & 27 & $22 \%$ \\
\hline Kindergarten - 5th grade & 57 & $46 \%$ \\
\hline 6th - 8th grade & 20 & $16 \%$ \\
\hline 9th -12 th grade & 18 & $14 \%$ \\
\hline
\end{tabular}

tutor, and staying home with a nonhousehold member.

Respondents reported that their preferred options in the event of prolonged school closures and/or a child's need to quarantine included an e-learning site offered by the employer on the employer's campus (22\%), financial resources to support childcare and e-learning (22\%), and off-campus e-learning site offered by the employer (16\%). Few respondents preferred third-party, off-campus e-learning sites with guaranteed spaces, discounts for health care-provider parents' children, and assistance in arranging e-learning pods between employees. Requests for working from home, flexible hours to take paid or unpaid time off for childcare, using paid time off without penalty, and reduced hours were also common sentiments. Regarding using an off-campus e-learning site, most participants were willing to drive up to 24 minutes (87\%).

Most notably, health care-provider parents' responses to, "Is there anything else you would like us to know?" were astounding:

- $\quad$ "Dual working parents ... Financially, it is a big strain on us to pay for childcare/e-learning in the case of quarantine."

- $\quad$ "There is no easy solution. As a [health care worker], we must be at work to care for our patients. Finding childcare to help at home has been extremely challenging and expensive."

- " $[$ This] is an eye-opening experience for us that it is possible to allow some flexibility for parents in the work environment to have the opportunity to work from home."

- "I just cannot afford additional childcare. I live paycheck to paycheck as it is."

- "Many single parents like me are struggling with major stress and fear of schools closing again."

\section{DISCUSSION}

There are serious support needs for health care providers who are parents during the COVID-19 pandemic. Nearly three quarters of children of the respondents were elementary school aged or younger. This is significant since school closures and childcare supervision needs are highest during such ages. Few daycare facilities remained open during the COVID-19 lockdown, but even they were subject to closures if attendees tested positive for COVID-19. Nonetheless, there was considerable discrepancy between currently available childcare options and preferred options among respondents. Additionally, respondents were asked to rate their stress level regarding reliable and available childcare for the next academic year, for which the average was 6 out of 10 .

It is accepted that poor wellness and moderate to severe burnout of health care workers are associated with worse patient safety. ${ }^{4}$ All health care team members, including prescribers, nursing staff, office staff, and other support staff, are essential for providing optimum care for patients. Therefore, supporting health care providers who are parents during the COVID-19 pandemic is essential to continuing to provide uninterrupted high-quality care. Of note, evidence suggests that structural or organizational interventions (eg, duty hour requirements) can meaningfully decrease burnout among clinicians, like their individual-focused counterparts (e.g., stress management training). ${ }^{5}$ Various efforts have been made to support childcare obligations of health care workers, especially for people in early training, including on-site childcare $^{6}$ and financial aid programs to support childcare costs. ${ }^{7,8}$

The Department of Pediatrics at the University of South Florida has implemented several strategies to address these needs that enable staff to continue to work, avoid using annual leave, and assist the medical group with areas that need help. The strategies include:

1. A back-up system was implemented for staff and faculty who cannot come to work, thereby decreasing the administrative burden of finding last-minute coverage and lessening the worry for physicians and staff.

2. Nurses and/or medical support staff can work from home managing the electronic medical record task boxes, making phone calls, and scheduling/rescheduling appointments.

3. Nursing or support staff can assist other clinical areas that need support. For example, a family medicine nurse working from home may be able to assist with tasks for pediatric or medicine clinical staff.

4. Health care workers can provide telemedicine visits from home.

Large groups whose members have built up a large amount of annual leave could also develop a pool where employees can donate accrued annual leave for others. Other options could include working with group administration toward contracted discounts at local community care groups, such as the YMCA. If the organization is not large enough to 
achieve this alone, office management or physicians can cooperate between medical groups to contract with a community childcare site. If the group has a human resources department, access to personal financial courses, personal coaching, and discounts for another childcare facility might be available. Finally, direct financial resources are especially difficult, given the current economic situation, but are a direct alleviation of a major source of stress for many parents.

\section{CONCLUSIONS}

Essential health care workers who are parents are in a uniquely stressful situation during the COVID-19 pandemic. However, coming together as a community in support of each other can lessen the stress of childcare and, therefore, improve uninterrupted patient care and the livelihood of our health care-provider parent peers.

\section{REFERENCES}

1. Patrick SW, Henkhaus LE, Zickafoose JS, et al. Well-being of parents and children during the COVID-19 pandemic: a national survey. Pediatrics. 2020;146(4):e2020016824. https://doi. org/10.1542/peds.2020-016824

2. Aoyagi $Y$, Beck CR, Dingwall $R$, NguyenVan-Tam JS. Healthcare workers' willingness to work during an influenza pandemic: a systematic review and meta-analysis. Influenza Other Respir Viruses. 2015;9(3):120130. https://doi.org/10.1111/irv.12310

3. Bayham J, Fenichel EP. Impact of school closures for COVID-19 on the US health-care workforce and net mortality: a modelling study. Lancet Public Health. 2020;5(5):e271-e278. https://doi. org/10.1016/s2468-2667(20)30082-7

4. Hall LH, Johnson J, Watt I, Tsipa A, O'Connor DB. Healthcare staff wellbeing, burnout, and patient safety: a systematic review. PLoS One. 2016;11(7):e0159015. https://doi. org/10.1371/journal.pone.0159015
5. West CP, Dyrbye LN, Erwin PJ, Shanafelt TD. Interventions to prevent and reduce physician burnout: a systematic review and meta-analysis. Lancet. 2016;388(10057):2272-2281. https://doi. org/10.1016/s0140-6736(16)31279-x

6. Snyder RA, Tarpley MJ, Phillips SE, Terhune $\mathrm{KP}$. The case for on-site child care in residency training and afterward. J Grad Med Educ. 2013;5(3):365-367. https://doi. org/10.4300/jgme-d-12-00294.1

7. Key LL Jr. Child care supplementation: aid for residents and advantages for residency programs. J Pediatr. 2008;153(4):449-450. https://doi.org/10.1016/j.jpeds.2008.05.028

8. Magudia K, Ng TSC, Bick AG, et al. Parenting while in training: a comprehensive needs assessment of residents and fellows. J Grad Med Educ. 2020;12(2):162-167. https://doi.org/10.4300/JGME-D-19-00563.1 